\title{
Needs, motivations, and identification with teaching: a comparative study of temporary part-time and tenure-track health science faculty in Iceland
}

\author{
Abigail Grover Snook ${ }^{1,2,3^{*}}$ (D), Asta B. Schram², Thorarinn Sveinsson ${ }^{1,2,4}$ and Brett D. Jones ${ }^{5}$
}

\begin{abstract}
Background: About 70\% of teachers who instruct healthcare students are considered sessional (adjunct/temporary part-time) faculty and receive limited instruction in pedagogy. Sessional faculty may feel isolated and struggle with their teacher identity, and are often assumed to vary in their commitment, motivation, and ability to teach. However, research on teaching identity, motivations, and needs of sessional faculty is lacking. The aim of this study was to compare similarities and differences between sessional and tenure-track faculty across a health science school to guide faculty development for sessional faculty.

Methods: We developed an online needs assessment survey, based on informal interviews and literature reviews. Seventy-eight tenure-track faculty and 160 sessional faculty completed the survey (37, 25\% response rate, respectively). We used validated scales to assess intrinsic motivation, identified regulated motivation, and identification with teaching, as well as developed scales (perceived connectedness, motivated by appreciation to try new teaching method) and single items. All scales demonstrated good internal consistency. We compared sessional and tenure-track faculty using t-tests/chi-square values.

Results: We found similarities between sessional and tenure-track faculty in intrinsic motivation, identified regulated motivation, and identification with teaching. However, sessional faculty perceived less department connectedness and were more motivated to improve instruction if shown appreciation for trying new teaching methods. Sessional faculty agreed more that they desired pedagogy instruction before starting to teach and that teachers should invest energy in improving their teaching. Admitting to less participation in activities to enhance teaching in the last year, sessional faculty were more interested in digital formats of faculty development.

Conclusion: Our comparison suggested that sessional faculty value being a teacher as part of their self, similar to tenured faculty, but desired more appreciation for efforts to improve and perceived less connectedness to their university department than tenured faculty. They also preferred digital formats for pedagogy to improve accessibility, prior to and throughout their teaching career to support their development as teachers. Using this information as a guide, we provide suggestions for faculty development for sessional faculty. Supporting sessional faculty in the health sciences should improve the quality of teaching and positively affect student learning.
\end{abstract}

Keywords: Sessional faculty, Motivation, Needs, Faculty development, Identity, Connectedness, Pedagogy, Nontenured, Adjunct, Part-time temporary, Self-determination theory

\footnotetext{
* Correspondence: snookabby@gmail.com

${ }^{1}$ Faculty of Medicine, University of Iceland, 101 Reykjavik, Iceland

${ }^{2}$ Health Sciences School, University of Iceland, 101 Reykjavik, Iceland

Full list of author information is available at the end of the article
}

(c) The Author(s). 2019 Open Access This article is distributed under the terms of the Creative Commons Attribution 4.0 International License (http://creativecommons.org/licenses/by/4.0/), which permits unrestricted use, distribution, and reproduction in any medium, provided you give appropriate credit to the original author(s) and the source, provide a link to the Creative Commons license, and indicate if changes were made. The Creative Commons Public Domain Dedication waiver (http://creativecommons.org/publicdomain/zero/1.0/) applies to the data made available in this article, unless otherwise stated. 


\section{Background}

Faculty development (FD) has been shown to positively affect student learning [1]. Needs assessments are often used to take into consideration the needs of educators being served by FD. Traditionally, educators are asked about their perceived need for skills [2-5]. However, authors of the Best Evidence Medical Education (BEME) Guide on faculty development initiatives in the health sciences state that "the majority of (FD) interventions emphasized skill acquisition, often ignoring faculty members' motivations for teaching, values, and professional identities" [6]. As FD interventions often challenge teachers to reflect on their teaching philosophy and consider modifying their current teaching practices, FD interventions need to build on the positive values and motivations that engage teachers, while providing the knowledge and skill that meets their perceived need [2, 7].

As students enter health sciences school, we assume that most are focused on becoming a good healthcare professional and not on becoming a good teacher. However, healthcare professionals may struggle with their identity as a teacher [8] as they find themselves teaching students as temporary part-time or, as they are referred to in Iceland and other parts of the world, sessional faculty (SF). Referred to by many other names across cultures and disciplines (e.g., adjunct, part-time, contingent, occasional, casual, non-tenured, community-based preceptors), SF are often appointed as non-tenure track and have a contractual, part-time relationship with their institution [9]. For this study, we defined SF as healthcare professionals who taught health science students directly in the classroom and/or clinic and were considered temporary, whereas tenure-track faculty (TF) were defined as all faculty hired for a permanent position.

SF are being called the "new faculty majority" [10]. They are gaining attention in research due to their prominence, with a U.S. study reporting $70 \%$ of all faculty are not hired on the tenure track [11]. Percentages of non-permanent faculty are difficult to report across Europe due to the heterogeneity of systems across and within countries [12], but the European University Institute reports that about $50 \%$ of faculty positions are fixed-term contracts in the United Kingdom [13]. Some researchers question whether the needs of SF are being met $[9,14,15]$, especially in the areas of preparation for teaching and ongoing training. SF may vary in terms of their backgrounds, teaching abilities, and motivational levels for teaching students, which has led to questions about SF quality of instruction, loyalty, and the impact on student learning [16]. The Association of American Medical colleges reports that SF often feel that their status causes both the institution and their colleagues to doubt their commitment and work ethic [17], which may contribute to feelings of not being understood or appreciated. Weimer [18] states that SF may differ from TF with respect to certain needs, such as: 1) pedagogical - based on their limited exposure to teaching theories; 2) a sense of connectedness to the university, departmental colleagues/other SF; and 3) time for FD opportunities. Forbes et al. [19] writes that it is imperative that SF needs are assessed and addressed as a necessary first step to promote job satisfaction and quality in teaching among SF in nursing.

However, considering US research in the health sciences, SF are not well-represented in needs assessments and FD. In a report by the Alliance for Academic Internal Medicine, the authors suggest that little information is available regarding the experiences, satisfaction and engagement of SF [20]. Drowos et al. [21] reports that most FD for SF is based on informal conversations and teaching evaluations, rather than needs assessments. The conclusion then is that, without needs assessments, little is known about the unique professional needs, motivations to teach, and identity of SF [22], making it difficult to develop effective support for this 'faculty majority'.

Although a few studies examine SF motivations to teach within the health sciences [23-26], most are qualitative, study a specific group within SF, and do not compare the results to TF. Therefore, we set out to answer the question: Do SF differ from TF with respect to their identification with teaching, motivation, connectedness with their department and faculty development needs across a health sciences school? We propose that a comparison of these two groups could suggest ways in which FD for SF should be different from FD for TF. Therefore, the aim of this study was to provide results that can guide FD for SF, by sending out a survey to both the $\mathrm{TF}$ and the SF in a health science school to compare measures of motivation, attitudes, values, and needs, highlighting similarities and differences.

\section{Methods}

Site, distribution, and participants

We performed this study at the Health Sciences School at the University of Iceland (HSS). HSS consists of six faculties: nursing, pharmacy, food science and nutrition, psychology, odontology, and medicine (which includes physical therapy, biomedical sciences and radiology). HSS has 212 TF and reportedly over 1000 SF [27], meaning SF comprise over $82 \%$ of teachers. To the best of our knowledge, no formal needs assessment of HSS teachers, whether SF or TF, has ever been conducted.

We obtained TF email addresses through online resources for HSS as well as distributions across disciplines and gender. No centralized list of health science SF email addresses was available from the university, so a list was generated through various resources. We 
coded SF and TF email addresses for incentive awards (\$20 gift cards) and only the primary researcher had access to the codes to preserve anonymity. For both the pilot and the main study, the primary researcher sent the invitation to participate from the HSS faculty developer (second author of this paper) email, explaining its purpose as an anonymous needs assessment and encouraging participation, while including the code and a link to the online survey. A few departments agreed to send out general encouragements to their faculty to participate. Once the participant entered the online survey, the purpose of the anonymous survey was again explained, the participant was given the primary authors' contact information for any questions, and it was explained that the results would be utilized for publications with all self-identifying information removed. The primary author sent reminders after two weeks to teachers who had not participated. Participation in the survey served as consent for participation in the study.

\section{Survey development}

Following the AMEE Guide for developing questionnaires [28], we performed a literature review of theories related to faculty needs assessment and a review of recent surveys $[2,3,5,19,29,30]$, which was synthesized with teacher interviews into a survey. We included previously validated scales that assessed the constructs described here. Identification with teaching (ID) is a 4-item scale, adapted from engineering, to evaluate identification with a profession [31]. ID is a measure of the extent to which a teacher values their role and performance in teaching as an important part of self [32]. Intrinsic motivation (IM) is a 4-item scale used as part of the Physician Motivation Teaching Questionnaire (PMTQ) [33]. IM is a construct within self-determination theory (SDT) and involves the highest form of self-regulation [34], where actions are done out of pure interest or joy. Identified regulated motivation (IR) is a 3-item scale, also part of the PMTQ [33]. IR, also part of SDT, is considered close to IN, with actions based on personal values and beliefs.

We also developed two scales based on the literature review: [1] a 3-item scale of teachers' perceived connectedness with their department/colleagues (CO) and [2] a 4-item scale of motivations to try a new teaching method by forms of appreciation (AP) (acknowledgment, financial compensation, supervisor feedback, improved student evaluations). We also included items that measured perceived need for more pedagogy before starting to teach, attitudes towards teachers' responsibilities to improve teaching, participation in faculty development activities in the last year, and FD format preferences. We chose to have our participants rate most items on a 6point Likert scale (1- "strongly disagree", 2- "disagree",
3- "somewhat disagree", 4- "somewhat agree", 5- "agree", and 6- "strongly agree") as we were interested in the strength of their agreement/disagreement. We did give an option of "choose not to answer". For preferred FD formats, we utilized a 5-point Likert scale (1- "never"; 2- "very unlikely"; 3- "unlikely"; 4- "likely"; 5- "very likely"). A copy of the entire survey in English is available upon request from the primary author.

We utilized suggested guidelines [35] for the adaptation of the survey to Icelandic, which included translation by a bi-lingual expert into Icelandic, synthesis, back-translation by a second bi-lingual expert into English, review by an expert committee, and pilot-testing with review. Thirty-two TF and 48 SF from HSS participated in the online pilot testing conducted a month prior to general administration of the survey. Icelandic translation of validated scales showed similar internal consistency to previously reported measures with all scales showing good internal consistency with Cronbach's alpha $(\alpha)$ [36], as listed in Table 1 along with the complete list of items for ID, IR, IM, CO, and AP scales.

\section{Ethical considerations}

We submitted the details of the project to The National BioEthics Committee. In response, they indicated there was no need for their approval given the nature of the data being anonymous opinions of faculty. We announced the project to the Icelandic National Data Protection Authority who publicized the project as per Icelandic regulations. This research was part of the primary author's doctoral study that was approved by the University of Iceland School of Health Sciences. The two primary researchers who sent the invitation emails had no position of authority over the participants and participation in the survey was voluntary and anonymous.

\section{Data analysis}

Pilot testing identified no single item measures that were problematic due to the translation process; therefore, we added the pilot data to the main data collected for full analysis. For all statistical analyses of final data, we utilized SAS 9.4 (SAS Institute Inc., Cary, North Carolina, USA). We calculated a total scale score by summing the scale items, and then divided the total by the number of items to determine the average scale score. Independent-sample $\mathrm{t}$-tests were used to identify similarities and significant differences between SF and TF for the five scales.

To eliminate cells with values less than five in the chisquare test, we combined the "strongly disagree", "disagree", "somewhat disagree", and "somewhat agree" statements into one category. For preferred FD format, we combined "likely" and "very likely" scores into one category and "never", "very unlikely", and "unlikely" scores into another category. We then calculated chi- 
Table 1 Scales - internal reliability and items

\begin{tabular}{|c|c|c|}
\hline a, a from literature & Scale name & Scale items \\
\hline \multirow[t]{4}{*}{$.80, .84[31]$} & \multirow[t]{4}{*}{ Identification with teaching (ID) } & Success in teaching is very valuable to me \\
\hline & & It matters to me how well I do with my teaching \\
\hline & & Being good at teaching is an important part of who I am \\
\hline & & Doing well as a teacher is very important to me \\
\hline \multirow[t]{4}{*}{$.86, .82[33]$} & \multirow[t]{4}{*}{ Intrinsic motivation (IM) } & I enjoy teaching most of the time \\
\hline & & I look forward to my next teaching most of the time \\
\hline & & During teaching, I am completely in my element \\
\hline & & Teaching enriches my job \\
\hline \multirow[t]{3}{*}{$.80, .65[33]$} & \multirow{3}{*}{$\begin{array}{l}\text { Identified regulated motivation (IR) } \\
\text { "I teach because..." }\end{array}$} & I find the contents of my lesson important \\
\hline & & $\begin{array}{l}\text { I am convinced that it is a healthcare professional's duty to } \\
\text { pass on his/her knowledge }\end{array}$ \\
\hline & & $\begin{array}{l}\text { it's important for me to make my contribution to students } \\
\text { becoming good healthcare professionals in the future }\end{array}$ \\
\hline \multirow[t]{3}{*}{0.78} & \multirow[t]{3}{*}{$\begin{array}{l}\text { Perceived connectedness with } \\
\text { department (CO) }\end{array}$} & $\begin{array}{l}\text { Department members frequently share teaching methods } \\
\text { they have found successful }\end{array}$ \\
\hline & & I feel connected to my department colleagues \\
\hline & & $\begin{array}{l}\text { I have specific department colleagues whom I would look } \\
\text { to for help if I wanted to improve my teaching methods }\end{array}$ \\
\hline \multirow[t]{4}{*}{0.76} & \multirow{4}{*}{$\begin{array}{l}\text { Motivated by appreciation (AP) } \\
\text { "I would be motivated to try a } \\
\text { new teaching method..." }\end{array}$} & $\begin{array}{l}\text { if I was financially rewarded for attending course and workshops } \\
\text { on enhancing my teaching }\end{array}$ \\
\hline & & $\begin{array}{l}\text { if I received feedback from other teachers or my supervisor on } \\
\text { my teaching }\end{array}$ \\
\hline & & if it improved my ratings on student evaluations \\
\hline & & if I was shown appreciation for enhancing my teaching methods \\
\hline
\end{tabular}

square values to identify differences between SF and TF for single item measures. We performed a two-way ANOVA on all significant scales and single item measures (other than preferred FD format) with the teacher type (SF or TF) and levels of [1] gender (male or female), [2] age group $(<40,40-52$, or $53+)$, and [3] discipline (nursing, medicine, or physical therapy) to test for interactions between them.

\section{Results}

Between the pilot testing and general administration of the survey, we emailed 863 invitations to participate to TF $(n=212)$ and SF $(n=651)$. Although 298 faculty members entered the survey, we collected demographic information (i.e., gender, age range, faculty discipline within HSS, SF or TF, and number of classroom teaching hours for SF) at the conclusion of the survey and we discarded data for the comparison if demographic information was not complete. Seventy-eight TF and 160 SF (or 238 faculty in total) completed the survey and demographic information for a response rate of 37 and 25\%, respectively. SF who teach in the classroom averaged 40 $\mathrm{h}$ a year of teaching (range $2-813 \mathrm{~h}$, median $=16 \mathrm{~h}$ ), or $1.3 \mathrm{~h} /$ week. A comparison of the demographic information of our TF and SF is presented in Table 2. We saw in our comparison of the TF survey respondents to the TF reported by the university that the survey respondents were an approximate representation of the disciplines at HSS but had a higher percentage of females. We could not perform the same comparison for SF as the information on SF was limited to their email addresses. In Table 2, we also compared the SF survey

Table 2 Participant Characteristics

\begin{tabular}{|c|c|c|c|c|}
\hline & \multicolumn{2}{|l|}{ TF } & \multicolumn{2}{|l|}{ SF } \\
\hline & $\mathrm{R}(\% \mathrm{~F})$ & $\mathrm{S}(\% \mathrm{~F})$ & $\mathrm{R}$ & $\mathrm{S}(\% \mathrm{~F})$ \\
\hline \# of participants & $212(45)$ & $78(62)$ & 651 & $160(71)$ \\
\hline$\%$ Med & $56(36)$ & $54(42)$ & * & $66(64)$ \\
\hline$\% \mathrm{RN}$ & 15 (87) & 19 (87) & * & 22 (94) \\
\hline$\%$ N\&FS & $6(46)$ & $8(67)$ & * & 1 (100) \\
\hline$\%$ Odont & $9(25)$ & $6(40)$ & * & $2(50)$ \\
\hline$\%$ Pharm & $6(57)$ & $5(25)$ & * & $4(66)$ \\
\hline \% Psych & $8(50)$ & $8(67)$ & * & $5(40)$ \\
\hline$\%>52$ years old & $*$ & 54 & $*$ & 38 \\
\hline
\end{tabular}

TF = tenured faculty; SF = sessional faculty;

$\mathrm{R}$ - reported by university; $\mathrm{S}$ - survey respondents; $\% \mathrm{~F}$ - percent female; Med - faculty of medicine (includes physical therapy, biomedical sciences, radiology); RN - faculty of nursing; N\&FS - faculty of nutrition and food science; Odont - odontology; Pharm - pharmacy; Psych - psychology; *information not known 
respondents to TF survey respondents, indicating that the SF group had a higher percentage of females and medicine faculty (includes physical therapy, biomedical sciences, and radiology), and was younger. Due to these differences, we performed a two-way analysis of variance, which indicated that interaction effects of teacher type with gender, age group and discipline were non-significant for scales and items (discussed below).

A comparison between SF and TF across our motivation (IM, IR), identity (ID), connectedness (CO), and appreciation (AP) scales, using independent t-tests is presented in Table 3. We saw similarities and differences between $\mathrm{SF}$ and TF. The $p$ values indicated that there were no significant differences between TF and SF with respect to intrinsic motivation (IM), identified regulated motivation (IR), and identification with teaching (ID), but inter-individual variation did exist as seen in measures of standard deviation (SD). In contrast, as evidenced by the $p$ values, there were significant differences with SF demonstrating significantly less connectedness (CO) and more motivation to try a new teaching method if shown appreciation (AP) than TF. Our developed scales $(\mathrm{CO}, \mathrm{OP})$ had higher inter-individual variation (SD), lower average scores (M), and more participants who chose not to answer, as indicated by the degrees of freedom (DF), when compared to our validated scales (ID, IM, IR).

Table analysis with chi-square testing is provided in Table 4 for single items that evaluated attitudes towards and participation in activities to improve teaching. Again, we saw some differences between SF and TF as indicated by significant $p$ values. SF significantly agreed more than TF that they would have liked more pedagogy before starting to teach, with $45 \%$ agreeing strongly with this statement. The $p$ values also indicated that $\mathrm{SF}$ agreed more that it is part of a teacher's responsibility to invest time and energy to improve teaching. With the largest $\mathrm{p}$ value difference, SF admitted more to not

Table 3 Scale Comparisons Between Tenured and Sessional Faculty

\begin{tabular}{|c|c|c|c|c|c|c|c|}
\hline \multirow[b]{2}{*}{ Scale } & \multicolumn{2}{|l|}{ TF } & \multicolumn{2}{|l|}{ SF } & \multirow[b]{2}{*}{ DF } & \multirow[b]{2}{*}{$t$} & \multirow[b]{2}{*}{$p$} \\
\hline & $\bar{M}$ & $\overline{\mathrm{SD}}$ & $\bar{M}$ & $\overline{\mathrm{SD}}$ & & & \\
\hline IM & 5.1 & 0.7 & 5.0 & 0.8 & 234 & 1.43 & 0.23 \\
\hline $\mathbb{I R}$ & 5.5 & 0.6 & 5.5 & 0.5 & 236 & 0.1 & 0.75 \\
\hline ID & 5.5 & 0.5 & 5.5 & 0.6 & 232 & 0.56 & 0.45 \\
\hline $\mathrm{CO}$ & 3.8 & 1.2 & 3.2 & 1.2 & 201 & 3.36 & $<.001$ \\
\hline$A P$ & 4.2 & 1.1 & 4.6 & 0.9 & 209 & 6.07 & 0.01 \\
\hline
\end{tabular}

$\mathrm{M}$ - average score; SD - standard deviation; DF - degrees of freedom; TF - tenured faculty; SF - sessional faculty;

IM - intrinsic motivation; IR - identified regulated motivation; ID - identification with teaching; CO - perceived connectedness; AP - motivated to improve by appreciation

Response options included: 1-strongly disagree; 2-disagree; 3-somewhat disagree; 4-somewhat agree; 5-agree; 6-strongly agree participating in activities in the last year to enhance teaching $(44 \%)$ compared to $13 \%$ of TF.

Table analysis and chi-square testing for significant preferred FD formats is presented in Table 5. SF preferred distance learning, hybrid learning, videoconferencing, and social networks when compared to TF, with distance learning being the most popular (67\%). The largest differences $(p<.001)$ were seen with the distance learning and social networks formats. Other formats that were asked about on the survey (e.g., workshops, consultations, in-person discussion groups) were not significant between groups.

\section{Discussion}

To the best of our knowledge, this is the first quantitative survey across an entire school of health sciences comparing the motivations, attitudes, values, and needs of both SF and TF. Our response rate is modest, possibly due to the survey length, but comparable to other needs assessments [2, 3, 29]. It is difficult to determine how representative our results are for the actual SF population since the university lacks information on this group, a problem also experienced in other studies [37, 38]. However, our results have value in illuminating the needs of an under-represented group of teachers who play an important role in health science education. We believe the results contribute to a better understanding of the similar and different motivations and needs of both TF and SF at a health sciences school and can help universities support all health science faculty.

\section{Similarities between SF and TF Intrinsic/identified regulated motivation and identification with teaching}

The results from this study suggest that there is no difference in intrinsic motivation between SF and TF (Table 3). Both TF and SF agree that teaching is enjoyable and personally fulfilling, which is encouraging to see. This is similar to a report of SF in nursing where participants describe their work as 'positive' and 'rewarding' [39] and in qualitative studies with SF hospital physicians who describe 'the joy of teaching itself' [24, 25]. Results from Steinert and Macdonald [23] "suggest that we should acknowledge our teachers, nurture their inherent desire to teach, and make the joy of teaching more visible." According to our results, the environment provided at HSS seems to be supporting both SF and TF interest and enjoyment of teaching fairly well.

The results also suggest that there is no difference in identified regulated motivation between SF and TF (Table 3). IR includes the values and beliefs integrated into a teacher that become his/her reasons to teach. Altruistic statements (e.g., "teaching is a healthcare professional's duty") are strong in the health sciences and are 
Table 4 Item Comparisons

\begin{tabular}{|c|c|c|c|c|c|c|c|c|c|}
\hline & & & DSA & A & SA & DF & SS & Chi-square & $p$ \\
\hline \multirow{4}{*}{$\begin{array}{l}\text { I would have liked more pedagogy } \\
\text { before I started teaching }\end{array}$} & \multirow[t]{2}{*}{ TF } & Count & 31 & 27 & 20 & \multirow[t]{4}{*}{2} & \multirow[t]{4}{*}{235} & \multirow[t]{4}{*}{7.92} & \multirow[t]{4}{*}{0.019} \\
\hline & & $\%$ within teacher type & $40 \%$ & $35 \%$ & $25 \%$ & & & & \\
\hline & \multirow[t]{2}{*}{ SF } & Count & 46 & 41 & 70 & & & & \\
\hline & & $\%$ within teacher type & $29 \%$ & $26 \%$ & $45 \%$ & & & & \\
\hline \multirow{5}{*}{$\begin{array}{l}\text { It is part of a teacher's responsibility } \\
\text { to invest time and energy } \\
\text { to improve teaching }\end{array}$} & \multirow[t]{2}{*}{ TF } & Count & 36 & 22 & 17 & \multirow[t]{5}{*}{2} & \multirow[t]{5}{*}{222} & \multirow[t]{5}{*}{7.31} & \multirow[t]{5}{*}{0.026} \\
\hline & & $\%$ within teacher type & $48 \%$ & $29 \%$ & $23 \%$ & & & & \\
\hline & \multirow[t]{3}{*}{ SF } & Count & 48 & 70 & 29 & & & & \\
\hline & & $\%$ within teacher type & $33 \%$ & $47 \%$ & $20 \%$ & & & & \\
\hline & & & $3+$ & 1 or 2 & 0 & & & & \\
\hline \multirow{4}{*}{$\begin{array}{l}\text { The number of times I participated } \\
\text { in activities that developed my teaching } \\
\text { methods in last year. }\end{array}$} & \multirow[t]{2}{*}{ TF } & Count & 33 & 35 & 10 & \multirow[t]{4}{*}{2} & \multirow[t]{4}{*}{238} & \multirow[t]{4}{*}{33.96} & \multirow[t]{4}{*}{$<.0001$} \\
\hline & & $\%$ within teacher type & $42 \%$ & $45 \%$ & $13 \%$ & & & & \\
\hline & \multirow[t]{2}{*}{ SF } & Count & 22 & 67 & 71 & & & & \\
\hline & & $\%$ within teacher type & $14 \%$ & $42 \%$ & $44 \%$ & & & & \\
\hline
\end{tabular}

DSA- strongly disagree, disagree, somewhat disagree, somewhat agree; A - agree; SA - strongly agree;

TF - tenured faculty; SF - sessional faculty

DF - degrees of freedom; SS - sample size; $\mathrm{p}$ - significance level

mentioned often in the literature among all types of faculty [23-26]. As these values are similar and just as strong in SF, our results contradict suggestions that SF are less motivated and committed to passing on their knowledge to students [17] and suggest that SF have strong professional values regarding teaching.

Deci and Ryan (34, pg. 182), in describing SDT, state that autonomous motivation is "both intrinsic motivation and the types of extrinsic motivation in which people have identified with an activity's value and ideally will have integrated it into their sense of self". Therefore, the combination of similar scores on both IM and IR suggest that SF and TF have similar autonomous motivation for teaching. Supporting autonomous motivation maximizes functioning and well-being in both students and faculty [40], so we suggest it would be

Table 5 How likely are you to participate in FD with following formats?

\begin{tabular}{|c|c|c|c|c|c|c|c|c|}
\hline & & & UL & $\mathrm{LL}$ & DF & SS & Chi-square & $p$ \\
\hline \multirow[t]{4}{*}{ Distance learning } & TF & Count & 50 & 28 & 1 & 238 & 20.5 & $<.001$ \\
\hline & & $\%$ within teacher type & $64 \%$ & $36 \%$ & & & & \\
\hline & SF & Count & 53 & 107 & & & & \\
\hline & & $\%$ within teacher type & $33 \%$ & $67 \%$ & & & & \\
\hline \multirow[t]{4}{*}{ Hybrid learning } & TF & Count & 41 & 37 & 1 & 238 & 4.5 & 0.035 \\
\hline & & $\%$ within teacher type & $53 \%$ & $47 \%$ & & & & \\
\hline & SF & Count & 61 & 99 & & & & \\
\hline & & $\%$ within teacher type & $38 \%$ & $62 \%$ & & & & \\
\hline \multirow[t]{4}{*}{ Videoconference } & TF & Count & 51 & 27 & 1 & 238 & 5.4 & 0.02 \\
\hline & & $\%$ within teacher type & $65 \%$ & $35 \%$ & & & & \\
\hline & SF & Count & 79 & 81 & & & & \\
\hline & & $\%$ within teacher type & $49 \%$ & $51 \%$ & & & & \\
\hline \multirow[t]{4}{*}{ Social networks } & TF & Count & 55 & 23 & 1 & 238 & 14.4 & $<.001$ \\
\hline & & $\%$ within teacher type & $71 \%$ & $29 \%$ & & & & \\
\hline & SF & Count & 71 & 89 & & & & \\
\hline & & $\%$ within teacher type & $44 \%$ & $56 \%$ & & & & \\
\hline
\end{tabular}

FD - Faculty Development; TF - tenured faculty; SF - sessional faculty

UL - never, very unlikely, and unlikely; LL - likely, very likely

DF - degrees of freedom; SS - sample size; $p$ - significance 
advantageous to encourage and celebrate IR and IM in all teachers.

The results also suggest that there is no difference in identification with teaching between TF and SF (Table 3 ). ID is a representation of how much a person values their role/performance in teaching, as a part of their self, as part of their identity [41]. We consider this a somewhat surprising result as a common assumption is that SF do not value being a teacher as much as TF. This is assumed because teaching is most often a secondary profession to their work as a healthcare professional, as evidenced by our sample which has an average classroom teaching of $1.3 \mathrm{~h}$ per week. The fact that TF and SF report similar high values for ID seems to contradict assumptions that SF identify less with being a teacher and are less motivated and committed to teaching [16, 17] and indicate that they identify themselves as teachers similar to TF.

\section{Differences between SF and TF Less connectedness to department/colleagues}

Our results confirm the conclusions of many qualitative studies that found that SF perceive a lack of connectedness to their university departments/colleagues $[9,16$, $17,22,39,42]$ (Table 3). In SDT, connectedness is similar to relatedness and is considered a fundamental need for optimal functioning and growth [43]. Common descriptions of life as a SF in the literature include words like 'isolated', 'not belonging', 'limited contact with faculty', 'lack of institutional engagement', 'excluded', 'invisible' and 'outsiders' $[19,22]$. Buch et al. [9] report that the overwhelming challenge mentioned by SF is 'the sense of isolation and disconnectedness from their departments and colleagues'. SF are also excluded from course development and curriculum renewal, further removing them from essential planning functions at the university [39]. Not only do SF experience less connectedness but a longitudinal study suggests these feelings ultimately increase over time and affect faculty identity negatively [44]. Research studies are starting to appear in the literature on programs designed to address SF needs for more connectedness $[9,16,42]$ but there is still a lack of in-depth evaluations regarding program outcomes [14]. However, increasing a sense of connectedness for SF is hypothesized to improve retention of effective SF [19] and is associated with improved loyalty and satisfaction [45] and less reports of isolation by SF [9], which may improve teaching effectiveness and student outcomes.

\section{Motivated by appreciation}

Our study results also suggest that SF would be more motivated than TF to reflect on their teaching or try a new teaching method if they are shown forms of appreciation (Table 3). These forms of appreciation include general recognition, feedback from supervisors, financial compensation, and improved student evaluations. Although all are considered extrinsic forms of motivation by SDT, general recognition, feedback from supervisors, and improved student evaluations can be considered either identified regulation or introjected regulation, depending on whether the teacher is motivated by internalized values (identified regulation) or to avoid guilt or enhance pride (introjected regulation) [43]. They are, therefore, considered more supportive of autonomy than financial compensation, considered to be a form of external regulation by SDT [43].

All health educators alike cite a need for recognition of high-quality teaching $[4,46]$ and a sense of appreciation from others has been recognized as important to identity development as a health science educator [8]. However, a common complaint of SF is not feeling appreciated for what they contribute [4, 42, 47]. Hoyt [45] reports low ratings of perceived recognition among SF, even though it is identified as a primary motivator for loyalty and satisfaction. Similarly, SF complain of a lack of assessment of and feedback on their teaching, which can be perceived as a lack of caring by the department/ institution [22]. However, van den Berg et al. [29] reports that 'feedback on my teaching performance' is the strongest predictor of engagement in teaching faculty at a university medical center. Therefore, it appears that feedback regarding teaching and appreciation of good teaching will benefit SF. Better student evaluations will presumably improve any teacher's sense of appreciation, although some argue that overemphasis on student evaluations, as is seen in assessments of SF [22], can inhibit diversification of methods by teachers due to fear of receiving lower student evaluation grades and wasting students' time [48]. Results are not as clear about the need for financial compensation but more recent research shows that the loyalty of SF is partially predicted by honorariums $[9,45]$.

\section{More pedagogical training}

Our results indicate that SF desired more training in pedagogy before starting to teach, with over $71 \%$ of SF agreeing/strongly agreeing with this statement (Table 4). This supports results from qualitative studies that suggest that SF in the health sciences receive little, if any, training in teaching methods, and desire more training $[3,9,49,50]$. An important question persists in the health science professions: How can we expect our teachers to be effective and competent teachers if we rarely train them in teaching? A sense of competence has also been identified as essential for health science educator identity [8] and optimal functioning and growth according to SDT [43], and a lack of confidence 
in teaching ability has been identified as a barrier to teaching medical students [49].

\section{Responsibility to improve but not attending FD}

More SF than TF agree/strongly agree that it is part of their responsibility as a teacher to invest time and energy to improve their teaching, while $56 \%$ of SF state that they attended at least one activity to enhance their teaching in the last year, as compared to $87 \%$ of TF (Table 4). Little literature on SF attendance at FD activities exists. Buch et al. [9] reports $67 \%$ of SF participated in at least one activity in FD in the last year and Hoyt [45] reports $69 \%$ of SF agreeing/strongly agreeing that they had enhanced their teaching in the last year. Both studies report somewhat higher percentages than the current study report of 56\%. Part of SF support could include FD that is available in various formats favored by SF (e.g., distance and hybrid learning), as supported by results in Table 5. In support of all these conclusions, a qualitative analysis by Buch et al. [9] identifies the following encouragers for SF to attend FD: 1) convenient time; 2) digital/online formats unless there is a social aspect; 3) increasing SF awareness of FD workshops and offerings; 4) offering workshops that are relevant and have proven benefits to students; and 5) incentives (appreciation, financial compensation) to participate.

\section{Implications}

We suggest that useful information was obtained about SF and TF through the current survey. Our results support the fact that SF have similar motivations and values to TF and confirms that SF put their value of self in the role and performance of being a good teacher, even if it may be a secondary occupation. We suggest that the conclusion from these results should be that SF should not be "marginalized" or neglected by their institution/ department because of the presumption that they are not as motivated or committed to being a good teacher.

The results also reinforce the idea that SF have a need for connectedness that should be addressed by FD, departments, and the university. There are many suggestions in the literature of what this could entail. A few universities have developed unique SF orientations [9, 14, 50] and required courses that are compensated [21], so that new SF have a basic pedagogical background before they start teaching. Another important idea is a centralized office for SF within the department or university $[15,17]$ with updated contact information. This may improve awareness of FD among SF and the office can develop resources specific to $\mathrm{SF}$, such as orientations, webpages, evidence-based pedagogical strategies, classroom observations, and mentoring $[9,45,50]$. Within the department, SF can be invited to meetings, be a voice in department and curricular decisions, and meet with staff, department chairs, and other SF for both professional and social reasons $[19,39]$. Other ideas that have been found to be successful are faculty learning communities and book clubs for SF [9, 16, 51]. Focus groups and interviews with the SF group of interest can identify and guide solutions that work best for that population.

One way to address the inconsistency between SF desire/value of FD and actual participation is to make FD offerings convenient to SF (multiple times including after-work hours and/or through various innovative digital formats) [9, 21]. Recognition of good teaching and the efforts made to become a better teacher are essential, and pedagogical training for SF that is reimbursed or somehow acknowledged should become the standard [21], and be seen as an investment in teachers and students. FD has been shown to improve teacher identity by improving confidence in teaching ability, increasing relatedness to other faculty, and increasing credibility and legitimacy as educators [8], as well as positively affecting student learning [1]. Therefore, FD should be encouraged and accessible for all health science faculty.

\section{Limitations and suggestions for future research}

We acknowledge that there are limitations to the study. First, the survey was administered to faculty in only one health science school. Therefore, some of the results obtained could reflect specific issues within this health science school and not be generalizable to all health science schools. However, results from the literature are consistent with the results shown from the study, indicating that the faculty at HSS in Iceland are similar to faculty at other schools with respect to at least some of their beliefs. Second, we cannot say with certainty that the results of this sample are representative of the whole population of teachers at HSS given the response rate and the fact that there was a high representation of female faculty in our respondent population, a common problem in survey research. In future research, the response rate might be better if a shorter measure or a specific tool could be created from the current study survey, as our respondents' completion rate indicated there was some survey fatigue (298 entered the survey but 238 completed). This could then be repeated in other countries to evaluate for a more global response. Another demographic issue was the lack of a centralized list of SF, as we were only able to obtain valid email addresses for 651 of the estimated 1000 SF [27], despite multiple efforts to obtain them. This lack of effort by universities to collect basic contact information about SF is also reported in the literature $[37,38]$ and should be addressed by administrations and departments. Despite these uncertainties regarding demographics, we found 
that the make-up of our SF and TF groups with respect to gender, age, and discipline did not affect the significant results in our study. Third, this study did not focus on one of the main discrepancies between SF and TF the issue of pay and benefits. We did this purposefully in an effort to explore other motivational effects but acknowledge the impact that this discrepancy has on motivation.

More research is needed on the support needed and challenges faced by SF. FD will be more effective if the population it serves is better known so emphasis should be placed on needs assessments, utilizing focus groups to explore solutions. Further research studies should evaluate FD programs that highlight, focus on, and celebrate motivations to teach for their impact on teachers and, ultimately, on student learning.

\section{Conclusion}

SF have become the 'faculty majority' and we suggest that their needs, motivations and values need to be considered in FD. The act of assessing the needs of this population, prominent in numbers but not well-represented in research, is an important first step in addressing those needs [19]. Despite some assumptions about SF lacking commitment and identity as teachers, identification of self with role/performance in teaching, altruistic professional values, and enjoyment of teaching were found to be similar between SF and TF, suggesting no difference in their motivations to be good teachers and contribute to student learning. Effective FD should not only teach skills but also reinforce and celebrate these motivations to encourage all faculty to continue to develop as educators. We suggest times for renewal and reflection on personal and professional growth [23] as well as reflection on values, reasons to teach, and the enjoyment of being a good teacher, both as individuals and as a community.

The differences between SF and TF highlight some of the issues that need to be considered when designing FD for SF. FD for SF needs to teach skills relevant to SF while promoting both motivations to teach and connectedness with the department/university. Departments need to be creative in their ways to include SF and look for ways to show appreciation for good teaching and efforts to improve. Finally, FD for SF needs to consider timing and online/hybrid formats for their offerings to accommodate SF work schedules. We suggest that assessing and addressing the motivations and needs of all faculty that have contact with students has a beneficial impact on the learning environment and the quality of education in the health sciences.

\section{Abbreviations}

AP: Motivated to try a new teaching method by forms of appreciation;

CO: Perceived connectedness with their department/colleagues; FD: Faculty development; HSS: School of Health Sciences; ID: Identification with teaching; IM: Intrinsic motivation; IR: Identified regulated motivation; PMTQ: Physician Motivation Teaching Questionnaire; SDT: Self-determination theory; SF: Sessional/adjunct/contingent faculty; TF: Tenured faculty

Acknowledgements

Thank you to all the teachers who took part in the survey.

\section{Authors' contributions}

AGS, ABS, and BJ contributed to development of the survey and the analysis and interpretation of the results. TS provided statistical assistance. AGS was the major contributor in writing the manuscript. All authors read and approved the final manuscript.

\section{Authors' information}

AGS - P.T., M.S., M.Ed., is a former Assistant Professor and current Contingent Faculty and Doctoral student at the University of Iceland. Her interest is to encourage healthcare teachers to reflect and invest in being better teachers. ABS - Ph.D., is an Assistant Professor and Educational Developer at the School of Health Sciences at the University of Iceland. Her research area includes teaching strategies and their relationship to student motivation and self-regulation, as well as teacher motivation and development.

TS - Ph.D., is Professor in physiology at the Department of Physical Therapy at the University of Iceland. His research activity includes association between physical activity and various health measures and effect of fatigue on motor control.

BJ - Ph.D., is Professor and leader of the Educational Psychology program in the School of Education at Virginia Tech. His research includes (a) investigating how students' beliefs impact their motivation and (b) examining methods instructors can use to design instructional environments that support students' motivation and learning (http://www.theMUSICmodel. com).

\section{Funding}

The principal author, AGS, receives funding from The Doctoral Grants of The University of Iceland Research Fund. ABS received partial funding from The Academic Affairs Fund at the University of Iceland. No other forms of funding were received.

\section{Availability of data and materials}

The datasets used and/or analysed during the current study are available from the corresponding author on reasonable request.

\section{Ethics approval and consent to participate}

We sought ethical approval for the project through The National BioEthics Committee but they indicated there was no need their approval given the nature of the data. We announced the project to the Icelandic National Data Protection Authority who publicized it per Icelandic regulations. This research was part of the primary author's doctoral study that was approved by the University of Iceland School of Health Sciences. The two primary researchers who sent the invitation emails had no position of authority over the participants and participation in the survey was voluntary and anonymous.

\section{Consent for publication}

Not applicable.

\section{Competing interests}

The authors declare that they have no competing interests.

\section{Author details}

${ }^{1}$ Faculty of Medicine, University of Iceland, 101 Reykjavik, Iceland. ${ }^{2}$ Health Sciences School, University of Iceland, 101 Reykjavik, Iceland. ${ }^{3}$ Physical Therapy Department, University of Iceland, 101 Reykjavik, Iceland. ${ }^{4}$ Research Centre of Movement Science, 101 Reykjavik, Iceland. ${ }^{5}$ Virginia Polytechnic Institute and State University, Blacksburg, Virginia, USA. 
Received: 17 November 2018 Accepted: 30 August 2019 Published online: 11 September 2019

\section{References}

1. Condon W, Iverson ER, Manduca CA, Rutz C, Willett G, Huber MT, et al. Faculty development and student learning: assessing the connections. Bloomington, Indiana: Indiana University Press; 2016. p. 1-156.

2. Behar-Horenstein L, Garvan C, Catalanotto F, Hudson-Vassell C. The role of needs assessment for faculty development initiatives. J Fac Dev. 2014;28(2):75-86.

3. Bigbee JL, Rainwater J, Butani L. Use of a needs assessment in the development of an interprofessional faculty development program. Nurs Educ. 2016;41(6):324-7.

4. Huwendiek S, Mennin S, Dern P, Ben-David MF, Van Der Veuten C, Tonshoff B, et al. Expertise, needs and challenges of medical educators: results of an international web survey. Med Teach. 2010;32(11):912-8.

5. Schönwetter DJ, Hamilton H, Sawatzky JV. Exploring professional development needs of educators in the health sciences professions. J Dent Educ. 2015;79(2):11323.

6. Steinert Y, Mann K, Anderson B, Barnett BM, Centeno A, Naismith L, et al. A systematic review of faculty development initiatives designed to enhance teaching effectiveness: a 10-year update: BEME guide no. 40. Med Teach. 2016;38(8):769-786.

7. Sorinola O, Thistlethwaite J, Davies D, Peile E. Realist evaluation of faculty development for medical educators: what works for whom and why in the longterm. Med Teach. 2017;39(4):422-9.

8. van Lankveld T, Schoonenboom J, Volman M, Croiset G, Beishuizen J. Developing a teacher identity in the university context: a systematic review of the literature. High Educ Res Dev. 2017;36(2):325-42.

9. Buch $\mathrm{K}, \mathrm{McC}$ cullough $\mathrm{H}$, Tamberelli L. Understanding and responding to the unique needs and challenges facing adjunct faculty: a longitudinal study. Int J Educ Res. 2017;16(10):27-40.

10. Fuller R, Brown MK, Smith K, editors. Adjunct faculty voices: cultivating professional development and Community at the Front Lines of higher education. Sterling, VA: Stylus Publishing; 2017.

11. Kezar A, Maxey D. Troubling ethical lapses: The treatment of continguent faculty. Change. 2014;July/August:34-7.

12. League of European Research Universities. Tenure and tenure-track at LERU universities 2014. Available from: https://www.leru.org/files/Tenure-andTenure-Track-at-LERU-Universities-Full-paper.pdf.

13. United Kingdom, Academic Career Structure: European University Institute; 2018. Available from: https://www.eui.eu/ProgrammesAndFellowships/ AcademicCareersObservatory/AcademicCareersbyCountry/UnitedKingdom.

14. Knott G, Crane L, Heslop I, Glass BD. Training and support of sessional staff to improve quality of teaching and learning at universities. Am J Pharm Educ. 2015;79(5):72.

15. Pollart SM, Dandar V, Brubaker L, Chaudron L, Morrison LA, Fox S, et al. Characteristics, satisfaction, and engagement of part-time faculty at U.S. medical schools. Acad Med. 2015;90(3):355-64.

16. Bond N. Developing a faculty learning community for non-tenure track professors. Int J Higher Ed. 2015:4(4):1-12.

17. Bunton SA, Corrice AM. An exploration of part-time U.S. medical school faculty: A thematic overview. Washington, D.C.: Association of Amercian Medical Colleges; 2011. Contract No.: 9.

18. Weimer M. Essential teaching principles: a resource collection for adjunct faculty. Madison, Wl: Magna Publications; 2016.

19. Forbes MO, Hickey MT, White J. Adjunct faculty development: reported needs and innovative solutions. J Prof Nurs. 2010;26(2):116-24.

20. Linzer M, Warde C, Alexander RW, Demarco DM, Haupt A, Hicks L, et al. Part-time careers in academic internal medicine: a report from the association of specialty professors part-time careers task force on behalf of the Alliance for Academic Internal Medicine. Acad Med. 2009;84(10):1395400.

21. Drowos J, Baker S, Harrison SL, Minor S, Chessman AW, Baker D. Faculty development for medical school community-based faculty: a Council of Academic Family Medicine Educational Research Alliance study exploring institutional requirements and challenges. Acad Med. 2017;92(8):1175-80.

22. Jolley MR, Cross E, Bryant M. A critical challenge: the engagement and assessment of contingent, part-time adjunct faculty professors in United States community colleges. Community Coll J. 2014;38(2-3):218-30.

23. Steinert $Y$, Macdonald ME. Why physicians teach: giving back by paying it forward. Med Educ. 2015;49(8):773-82.

24. Dybowski $\mathrm{C}$, Harendza S. "Teaching is like nightshifts...": a focus group study on teaching motivations of clinicians. Teach Learn Med 2014;26(4):393-400.
25. May M, Mand P, Biert ZF, Hummers-Pradier E, Kruschinski C. A survey to assess family physicians' motivation to teach undergraduates in their practices. PLoS ONE. 2012; 7(9):e45846.

26. Dahlstrom J, Dorai-Raj A, McGill D, Owen C, Tymms K, Watson DA. What motivates senior clinicians to teach medical students? BMC Med Educ 2005;5:27.

27. Dietz TE. Human resources information [email]. In: Snook AG, editor. Reykjavik, Iceland2017.

28. Artino AR, La Rochelle JS, Dezee KJ, Gehlback H. Developing questionnaires for educational research: AMEE guide no. 87. Med Teach. 2014;36(6):463-474.

29. van den Berg BAM, Bakker AB, ten Cate TJ. Key factors in work engagement and job motivation of teaching faculty at a university medical centre. Perspect Med Educ. 2013;2:264-75.

30. Watts J, Econmou K, McGoldrick B. US postsecondary faculty in 2015. USA: Sponsored by the Bill and Melinda Gates Foundation; 2015.

31. Jones BD, Paretti MC, Hein SF, Knott TW. An analysis of motivation constructs with first-year engineering students: relationships among expectancies, values, achievement, and career plans. J Eng Educ. 2010;99(4):319-36.

32. Jones BD, Ruff C, Osborne JW. Fostering students' identification with mathematics and science. In: Renninger KA, Nieswandt M, Hidi S, editors. Interest in mathematics and science learning. Washington, DC: American Educational Research Association; 2015. p. 331-52.

33. Dybowski C, Harendza S. Validation of the Physician Teaching Motivation Questionnaire (PTMQ). BMC Med Educ. 2015;15(166).

34. Deci E, Ryan R. Self-determination theory: a macrotheory of human motivation, development, and health. Can Psychol. 2008:49:182-5.

35. Beaton DE, Bombardier C, Guillemin F, Ferraz MB. Guidelines for the process of cross-cultural adaptation of self-report measures. Spine. 2000;25(24):3186-91.

36. Kline TJB. Pyschological testing. Thousand Oaks, CA: Sage; 2005.

37. Kezar A, Sam C. Understanding the new majority of non-tenure-track faculty in higher education: demographics, experience, and plans of action (ASHE higher education report). San Francisco, CA: Jolley-Bass; 2010.

38. Linder KE. Creating space for adjunct faculty: the multiple roles of centers for teaching and learning. J Centers Teaching Learning. 2012;4:33-59.

39. Dixon KA, Cotton A, Moroney R, Salamonson Y. The experience of sessional teachers in nursing: a qualitative study. Nurs Educ Today. 2015;35(11):1097-101.

40. Lyness JM, Lurie SJ, Ward DS, Mooney CJ, Lambert DR. Engaging students and faculty: implications of self-determination theory for teachers and leaders in academic medicine. BMC Med Educ. 2013;13:151.

41. Osborne JW, Jones BD. Identification with academics and motivation to achieve in school: how the structure of the self influences academic outcomes. Educ Psychol Rev. 2011;23(1):131-58

42. Meixner C, Kruck SE, Madden LT. Inclusion of part-time faculty for the benefit of faculty and students. Coll Teach. 2010;58(4):141-7.

43. Ryan RM, Deci EL. Self-determination theory and the facilitation of intrinsic motivation, social development, and well-being. Am Psychol. 2000;55(1):68-78.

44. Thirolf $\mathrm{KQ}$. How faculty identity discourses of community college part-time faculty change over time. Community Coll J. 2013;37(3):177-84.

45. Hoyt JE. Predicting the satisfaction and loyalty of adjunct faculty. J Cont High Educ. 2012;60(3):132-42.

46. Schiekirka-Schwake S, Anders S, von Steinbüchel N, Becker JC, Raupach T. Facilitators of high-quality teaching in medical school: findings from a nation-wide survey among clinical teachers. BMC Med Educ. 2017;17(1):178.

47. Starr S, Ferguson WJ, Haley HL, Quirk M. Community preceptors' views of their identities as teachers. Acad Med 2003;78(8):820-825.

48. Herckis $L$, Scheines R, Smith J. Failure to embrace new teaching techniques not just about fear of embarrassment: Times Higher Education; 2017. [cited 2017 July 12]. Available from: https:/www.timeshighereducation.com/blog/failure-embrace-newteaching-techniques-not-just-about-fear-embarrassment.

49. McCullough B, Marton GE, Ramnanan CJ. How can clinician-educator training programs be optimized to match clinician motivations and concerns? Adv Med Educ Pract 2015;6:45-54.

50. Santisteban L, Egues AL. Cultivating adjunct faculty: strategies beyond orientation. Nurs Forum. 2014;49(3):152-8.

51. Valle M, Fuchs T. Teaching and learning communities: empowering adjuncts and ensuring quality. J Educ Hum Dev. 2015;4(1):1-6.

\section{Publisher's Note}

Springer Nature remains neutral with regard to jurisdictional claims in published maps and institutional affiliations. 